\section{A REESTRUTURAÇÃO POLÍTICO- ADMINISTRATIVA DO IMPÉRIO ROMANO NA ÉPOCA DE DIOCLECIANO E DA TETRARQUIA (284-305)}

\begin{abstract}
Diogo Pereira Silva*
RESUMO: Neste artigo, temos por objetivo analisar os fundamentos da reestruturação político-administrativa do Império Romano durante o governo de Diocleciano, considerando as pré-condições do século III, e as características que conformaram o poder imperial romano durante a época de Diocleciano e da Tetrarquia (284-305).
\end{abstract}

PALAVRAS-CHAVE: Diocleciano; Tetrarquia; Império Romano.

\section{LA RESTRUCTURATION POLITIQUE ADMINISTRATIVE DE L'EMPIRE ROMAIN À L'ÉPOQUE DE DIOCLÉTIEN ET LA TÉTRARCHIE (284-305)}

RÉSUMÉ: Le but de cet article est d'analyser les fondements de la restructuration politique et administrative de l'Empire Romain sous le règne de Dioclétien, compte tenu des conditions du IIIème siècle, et les caractéristiques qui ont façonné l'Empire romain à l'époque de Dioclétien et la Tétrarchie (284-305).

MOTS-CLÉS: Dioclétien; Tétrarchie; Empire romain.

\section{O IMPÉRIO ROMANO NO SÉCULO III: COLAPSO, CRISE OU OUTRA LÓGICA DE ORGANIZAÇÃO}

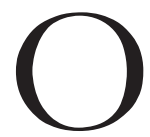

uso de metáforas no estabelecimento de analogias em explicações historiográficas é uma interessante ferramenta retórica que dá a liberdade ao historiador de criar uma representação mental para o leitor - a partir de dados de sua experiência sensível -, ao mesmo tempo em que lhe permite produzir eufemismos ou disfemismos sobre determinado assunto.

O século III no Império Romano, amplamente caracterizado como o período da "crise do século III", foi examinado por A.H.M Jones e Ramsay MacMullen a partir da metáfora do túnel mal iluminado e desconhecido. Tal túnel, por sua vez, separou dois mundos
* Doutorado em História Comparada pela Universidade Federal do Rio de Janeiro. Universidade Salgado de Oliveira. profdiogo.psilva@ gmail.com 
muito bem documentados e conhecidos: de um lado a Época dos Severos (193-235), e de outro, a Época de Diocleciano e Constantino (284-337). ${ }^{1}$

Em uma teorização bastante fortuita, Carlos Antonio Aguirre Rojas cunhou uma expressão que nos permite observar bem as características deste período para o Império Romano. Para Aguirre Rojas, há uma diferença entre séculos cronológicos e aquilo que denominou de "séculos históricos":

Os séculos históricos se constroem, de fato, a partir das diversas durações dos fenômenos que neles se desenvolvem, atribuindo temporalidade e sentido às diferentes curvas evolutivas que esses séculos representam. Então, o fim de um século histórico, diferente de um simples século cronológico, implica no fim dos mesmos processos fundamentais que lhe garantiram vigência e substância, virando a página da história, para inaugurar novos processos e novas situações, próprias do novo século e do novo ciclo histórico que se inicia. $^{2}$

Aquilo a que se convencionou denominar de "crise do século III" remete a um período de aproximadamente cinquenta anos, entre os anos 235 e 284 . Por certo, os acontecimentos da morte de Caracala (211-217) podem ser considerados uma prévia das várias situações de assassinato e conspiração comuns ao século III. Como em toda periodização, os marcos são bem discutíveis.

Em Era dos Extremos, o historiador inglês Eric J. Hobsbawm propôs uma periodização do século XX entre os anos 1914 e 1991, uma vez que este período possui características próprias, que o permitem analisá-lo como um "século histórico". Outrossim, o século III também pode ser considerado um "breve século III", que, ao mesmo tempo em que marca o fim de um tipo de organização própria ao Principado, lança os fundamentos das transformações estruturais que podem ser vistas na época de Diocleciano e da Tetrarquia.

Um túnel mal iluminado, um "breve século", este curto - e crucial - período da história romana, se comparado a outros períodos da história imperial, é bastante carente de registros textuais confiáveis, e produziu efeitos historiográficos conjugados, que foram observados por Alaric Watson, para o qual, até recentemente, as pesquisas acadêmicas sobre este período eram desencorajadas. Watson observa que a história deste século era ignorada ou tratada de forma concisa e resumida, o que acabava reiterando a imagem do "túnel". Ao mesmo tempo, o autor afirmou que a representação do século III como uma "Idade das Trevas de Roma" acabou por estimular explicações simplistas que atribuem todas, ou grande parte, das modificações observáveis entre no Império Romano a este curto período de tempo. ${ }^{3}$

A partir destas duas considerações, podemos afirmar que o desencorajamento das pesquisas sobre este século acabaram por favorecer interpretações que examinavam este

\footnotetext{
${ }^{1}$ Jones, 1964, p. 23; MacMullen, 1991, p. 111; Watson, 1999, p. 2.

2 Aguirre Rojas, 2007, p. 1.

${ }^{3}$ Watson, 1999, p. 2.
} 
período como puramente uma época de "crise", "catástrofe" e "declínio". Ademais, os desenvolvimentos graduais e as transformações estruturais de diferentes durações acabaram ignorados, quando não confundidos com rupturas.

No entanto, aplicar uma etiqueta de "crise" a este breve século é um tanto quanto enganador - auto-ilusão ao historiador, e tentativa de ilusão para o leitor. Por certo, para compreender este período da história romana, devemos manter um senso de proporção.

Primeiramente, é um tanto complicado defender a aplicação do termo "crise" a um período de aproximadamente meio século. Nenhuma estrutura de poder imperial poderia se sustentar após uma crise com tal duração, que não fosse intercalada por períodos de recuperação.

Em seguida, se tornou algo comum aos cientistas sociais fazer uso deste termo de forma genérica e indiscriminada, aplicando-o a diferentes mudanças nos domínios políticos, econômicos, culturais, militares e sociais que não coincidem, nem temporalmente nem espacialmente.

Esclarecido este ponto, aventamos a necessidade de uma abordagem mais discriminada, que estabeleça uma inter-relação entre os diferentes elementos mapeados, ao mesmo tempo em que busca inseri-los no contexto das transformações que estavam ocorrendo no Império Romano.

Neste sentido, referendamos aquilo que propusemos acima, uma vez que devemos nos desvencilhar de conceitos como "crise", "decadência romana" ou "anarquia militar", entendendo este "breve século III" em suas características específicas.

O mundo romano no século III era um lugar no qual as antigas certezas desmoronavam ante o impacto de forças novas e inesperadas. Era acima de tudo um mundo dominado por questões militares e, portanto, pelos exércitos. Os imperadores, aclamados pelas legiões, eram quase exclusivamente homens de origem humilde, promovidos mais pelo mérito que pelo pertencimento a determinada ordem. Neste contexto, a elite senatorial perdeu seus privilégios de acesso ao poder político, que progressivamente passava para as mãos dos grandes soldados, homens como Aureliano, Diocleciano e Constantino.

Durante o século IV, quando a tradição literária sobre a qual o nosso conhecimento deste período se baseia foi formada, as transformações políticas, econômicas e sociais do século anterior foram vistas em termos de um drástico e lamentável declínio. Os autores e seu público leitor pertenciam aos grupos educados dos uiri clarissimi e dos viri illustribus, que se identificavam com o ideário senatorial. Para tais escritores, na esteira da tradição de Salústio e Tácito, era natural atribuir os males de seu próprio século à erosão da dignidade e do poder senatorial, que passou para as mãos de rudes imperadores soldados.

De acordo com uma perspectiva conservadora, o século III foi representado como um momento desastroso de despotismo arbitrário. Tais noções faziam parte de uma ampla retórica do declínio que foi logo apropriada por autores pagãos e cristãos em suas obras de polêmica.

Até recentemente, os historiadores preocupados com este período compartilhavam das mesmas opiniões que os antigos, sendo a retórica do declínio pouco questionada. Este 
fator, combinado com a falta de documentação escrita da época, permitiu o desenvolvimento de análises que viam as transformações políticas, sociais, econômicas e culturais do século III sob o prisma de uma crise.

Nesta visão tradicional, a aparente estabilidade do século II soçobrou juntamente com o modelo urbano de organização, preponderante na época do Principado. Após este período de ruínas, surge o Dominado, com seu governo autocrático. Embora esta visão tenha passado recentemente por várias críticas, persiste a caracterização dicotômica entre o "Alto Império" e o "Baixo Império", em cuja cesura estaria a "crise do século III".

A crescente consciência desta retórica subjacente à documentação textual, junto a uma análise sistemática de outros tipos de documentação, encoraja outras abordagens, que observam as complexas transformações sociais e políticas do período, incluindo a diminuição da significação política do Senado, e só podem ser entendidas numa perspectiva de longa duração. $\mathrm{O}$ aumento das pressões externas e o seu efeito desestabilizador sobre o sistema político não produziram, mas aceleraram, tais desenvolvimentos estruturais.

Neste sentido, a ideia convencional de uma catastrófica "crise do século III" deveria ser abandonada. Ao mesmo tempo, é vital não minimizarmos a gravidade da situação política e militar. Nas décadas de 250 e 260, as incursões germânicas começaram a se intensificar cada vez mais profundamente no coração do mundo mediterrâneo, e desde a ameaça de Aníbal - durante a Segunda Guerra Púnica - Roma se encontrava numa posição vulnerável. Aparentemente, o caráter implacável da ameaça germânica ao longo do limes Reno-Danubiano, e o surgimento do Império Persa Sassânida, e posteriormente de Palmira no Oriente levaram a um ciclo de devastação das defesas militares, invasões estrangeiras e guerra civil.

$\mathrm{Na}$ época em que Aureliano ascendeu ao poder, em 270, o efeito acumulado desta situação de deterioração havia precipitado uma profunda, embora de curta duração, fragmentação do Império Romano que ameaçou a sua integridade política e territorial. Neste sentido mais restrito nos parece significativo falar de crise.

Entretanto, há algo que os historiadores parecem esquecer: a história do século III não é a história do colapso do Império Romano, pelo contrário este é um período no qual o mundo romano se adaptou, se transformou, e lançou base para a estruturação de uma nova identidade imperial, e de um novo sistema político que duraria ainda mais dois séculos no ocidente, e que só se reformaria no século VIII, no Oriente.

As questões do século III devem ser, deste modo, analisadas sob o prisma do agravamento das tensões latentes na sociedade imperial romana. Principalmente, diante do rompimento dos parâmetros inerentes ao sistema de domínio imperial: o parâmetro tecnológico, que impedia um grande crescimento da produção econômica, limites financeiros, recursos materiais em processo de estagnação diante do final das guerras de conquista; a baixa demográfica - diminuição da mão de obra produtiva, e de soldados disponíveis -, política externa marcada pelo avanço dos germanos e persas. 


\section{DESENVOLVIMENTO DE NOVAS LÓGICAS POLÍTICO-ADMINISTRATIVAS}

Em meio a intrigas e assassínios comuns ao século III, Diocleciano assumiu o poder imperial, em 284; encarou, por sua vez, os mesmos problemas que acossaram os imperadores que o haviam recentemente antecedido.

O primeiro problema com que teve que lidar era a existência de outro imperador legítimo, o filho de Caro (282-283), Carino (283-285), cujo irmão Numeriano (283-284) fora assassinado. Certamente, Carino não estava disposto a dividir o poder imperial com um usurpador, indispondo-se em uma guerra, no decorrer da qual acabou por ser executado por seus próprios soldados. ${ }^{4}$

Em seguida, Diocleciano teve que lidar com as invasões germânicas ao longo do limes Reno-Danubiano - as quais foram facilitadas pelo deslocamento de tropas, em decorrência de seu conflito com Carino -, e com o recrudescimento da guerra contra os persas - que se encontrava inconclusa desde a morte de Caro.

No caso da Gália, havia uma complicação extra: as revoltas relacionadas à opressão fiscal, às destruições materiais, e ao desenvolvimento do regime de colonato - o movimento

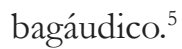

Durante os seguintes quinze anos, os exércitos romanos foram vitoriosos após uma série de campanhas desde a Britânia - onde o general Caráusio (287-293) se proclamou imperador -, até o Egito e Mesopotâmia, instaurando um período de relativa estabilidade política no Império Romano. ${ }^{6}$

Além das campanhas militares, havia outros problemas estruturais mais graves: o da crise econômica, o do ordenamento administrativo, e o da legitimidade e estabilização do poder imperial, de forma similar aos casos de Augusto e Severo que vimos anteriormente.

Do ponto de vista administrativo, a questão fulcral era estabelecer uma ligação entre o governo central - de onde se originavam as decisões - e os servidores locais - encarregados de pô-las em prática -, principalmente no que concerne às ações relativas à manutenção do Império.

Para tal, Diocleciano inicialmente reduziu o tamanho das províncias e incrementou seu número, agrupando-as em dioceses sob a jurisdição de um nicarius (originalmente um representante do prefeito do pretório), e nomeou vários prefeitos pretorianos, cada um deles responsável por uma grande região do Império. ${ }^{7}$

Os servidores nesta hierarquia não só tinham acesso a seus superiores imediatos, como também, em alguns casos, podiam se dirigir aos que ocupavam um escalão superior.

\footnotetext{
${ }^{4}$ SHA Carus et Carinus et Numerianus X,1.

${ }^{5}$ Silva, Mendes, 2006, p. 198, n. 76. Rodrigues Gervás, 1991; Van Dam, 1985.

${ }^{6}$ Sobre a Britânia sob Caráusio, ver Casey, 1977, p. 283-301; Silva, Pedreira, 2012, p. 123-145. Sobre o Egito na época da Tetrarquia, ver os estudos de Kalavrezou-Maxeiner, 1975, p. 225-251; Johnson, 1936; Wallace, 1938.

${ }^{7}$ Anderson, 1932, p. 24-32; Baynes, 1925, p. 195-208; MacMullen, 1964, p. 305-316.
} 
Os novos postos da administração civil foram ocupados em sua maior parte por indivíduos da ordem eqüestre que haviam servido o exército. ${ }^{8}$

Quanto à crise econômica pela qual passava o Império, havia a inflação e a irregularidade nos ingressos percebidos com os impostos. Eram estes, todavia, problemas de larga data. A primeira medida executada por Diocleciano foi uma reforma monetária, instituindo novas moedas valorizadas: o aureus, o argenteus, e o follis. Implementada em 294, acabou engendrando uma contrapartida inflacionária notável na primeira parte de seu reinado. ${ }^{9}$

Uma medida que buscou barrar a onda inflacionária foi a tentativa de congelamento de todos os preços mediante um edito publicado em 301 - o chamado Edito Máximo. ${ }^{10}$ Mais êxito teve a resolução dos problemas dos impostos e ingressos, através de uma pesada tributação como testemunhou Lactâncio anos depois. Desde muito tempo, o exército satisfazia suas necessidades recorrendo ao imposto denominado annona militaris, que recaia sobre a população local. Esta prática se converteu em imposto regular sob Diocleciano. ${ }^{11}$

\section{O SISTEMA POLÍTICO DA TETRARQUIA}

Sinteticamente, do ponto de vista político, punha-se diante de Diocleciano a seguinte questão: de que forma a continuidade do poder imperial poderia ser assegurada após a morte do Augusto reinante, sobre um território imenso como o do Império Romano?

De uma forma bem pragmática, a estratégia posta em ação pelo imperador foi a de colocar em prática, de forma ordenada, as experiências de governo que vinham sendo esboçadas desde meados do século III, no Império Romano.

Em curto prazo, a solução desenvolvida por Diocleciano para consolidar sua posição foi o exercício colegiado do poder imperial - a partir da divisão do imperium, e da competência administrativa com outros três colegas. Assim, a partir de 293, passaram a haver dois Augustos e dois Césares. Conforme a vigência deste arranjo, os Césares sucederiam aos Augustos, em caso de morte ou abdicação.

O ponto fundamental deste sistema eram as ligações familiares estabelecidas entre os Augustos e seus Césares, através de vínculos matrimoniais e laços de adoção. Criou-se assim uma Casa Imperial, com todos os membros inscritos na gens Valeria.

Do ponto de vista religioso, ocorre um fenômeno dúbio, a contradição entre o novo e a tradição. A novidade se relacionava à proteção especial de comites, deuses que eram considerados, literalmente, os "acompanhantes", os protetores dos quatro imperadores.

O tom tradicional se referia à escolha destas divindades, advindas do panteão clássico greco-romano, uma vez que figuravam em primeiro plano as divindades Júpiter -

\footnotetext{
8 Piganiol, 1949, p. 446; Silva, Mendes, 2006, p. 203-210.

${ }^{9}$ Erim, Reynolds, Crawford, 1971, p. 171-177; Hendy, 1972, p. 75-82; Mattingly, 1921, p. 254-264; Sperber, 1966, p. 190-195; Sutherland, 1955, p. 116-118; 1961, p. 94-97; 1967; p. 6.

${ }^{10}$ Jones, 1953, p. 293-318; Michell, 1947, p. 1-12; West, 1939, p. 239-245.

${ }^{11}$ Silva, Mendes, 2006, p. 210ss.
} 
sob cuja proteção especial se encontrava Diocleciano -, e Hércules - a divindade protetora de Maximiano, também conhecido como Hercúleo -, tidos como antepassados míticos da família imperial.

Neste sentido, observamos um ideário e mística imperiais que faziam dialogar os esquemas clássicos com os sistemas simbólicos que garantiam a aceitação universal e inquestionável do soberano no Baixo Império Romano, no caso, a proteção divina de um comes.

A este sistema político, usualmente, conferiu-se a denominação Tetrarquia. Por sua vez, não era uma simples solução a priori "maquinada" por Diocleciano, sendo, antes disso, resultante de um processo catalisado pelas pressões germânicas sobre o território da Gália.

O primeiro passo para este ordenamento foi dado quando Diocleciano elevou seu colega ilírico Maximiano (286-305; 307-310) - inicialmente à dignidade de César, e, logo em seguida - à dignidade de Augusto, em 286.

Certamente, conforme dissemos, este processo se baseou em ordenamentos políticos pré-existentes durante o século III - como o caso do governo de Valeriano e Galieno, ou mesmo a tripartição do Império entre Galieno, Tétrico e o Valabato. ${ }^{12}$

Em vista disto, organizou-se a partir do sistema simbólico próprio da época uma explicação para a relação entre Diocleciano e Maximiano. Embora este possuísse a mesma dignidade de Diocleciano, sendo seu irmão ${ }^{13}$ - frater -, sua autoridade era inferior à do Augusto Sênior.

A simbologia do sistema pode ser estabelecida da seguinte forma: Diocleciano, o filho de Júpiter, tinha como co-imperador Maximiano, o filho de Hércules, e, assim, descendente de Júpiter.

Esta distinção apresentava como apanágio a união dos Augustos em torno da concórdia e da unidade política. Não obstante os papéis estivessem bem delimitados, era Diocleciano quem dirigia a política e Maximiano Hercúleo quem a levava a cabo:

Por mais que os bens que nos cumulam o céu e a terra nos pareçam devidos à intervenção de diversas divindades, provêm não obstante das divindades soberanas, de Júpiter, senhor do céu, e de Hércules, pacificador da terra; da mesma forma, nas mais nobres empresas, ainda aquelas que se realizam sob o mandato imediato dos demais, Diocleciano é quem toma as iniciativas e tu [i.e. Maximiano] és quem as leva a cabo. ${ }^{14}$

Nesta passagem, o panegirista - Mamertino - aventou uma similitude existente entre o mitologema de Hércules, e sua relação com Júpiter - isto é, a vontade deste em gerar o maior dos heróis, aquele capaz libertar o mundo dos males. ${ }^{15}$

\footnotetext{
${ }^{12}$ Cizek, 1999 , p. $57-100$.

${ }^{13}$ Panegíricos latinos II (X), 1, 5; 4,1; 9, 1-3; cf. Lactâncio, Sobre a morte dos perseguidores, VIII,1.

${ }^{14}$ Panegíricos latinos II (X), 11, 6 (Tradução nossa). V tenim omnia commoda caelo terraque parta, licet diuersorum numinum ope nobis prouenire videantur, a summis tamen auctoribus manant, Ioue rectore caeli et Hercule pacatore terrarum, sic omnibus pulcherrimis rebus, etiam quae aliorum ductu geruntur, Diocletianus facem, tu tribuis effectum. ${ }^{15}$ Grimal, 2005, p. 206.
} 
Representava-se, através da utilização da referência mitológica, a relação entre Diocleciano e Maximiano. Este foi elevado à dignidade de Augusto para ajudar Diocleciano em sua tarefa de reordenamento do Império Romano.

Segundo os autores da época, Maximiano era um homem com espírito guerreiro, que executava prontamente os trabalhos imputados por Diocleciano. ${ }^{16}$ Entretanto, no ano de 290, inúmeras forças se alvoroçaram sobre o Império Romano, de forma que o sistema da diarquia não podia mais controlá-las de modo efetivo.

A rebelião do general Caráusio na Britânia, em 287, não somente levava perigo à Gália, como também, através de seus contatos com os povos do Baixo Reno, colocava em risco o domínio diárquico sobre a região; a defesa do limes danubiano não podia também ser negligenciada; e a leste o poderoso Império Persa sassânida organizava uma ofensiva.

Este foi o contexto no qual a decisão foi tomada, Diocleciano como imperador sênior, e fonte última da lei e do imperium, reestruturou o governo imperial estabelecendo uma tetrarquia, como forma de fazer frente às múltiplas frentes hostis.

Do ponto de vista militar, um dos primeiros reflexos da formação da Tetrarquia foi o aumento do número soldados, o que exigia cada vez maiores quantidades de suprimentos, obtidos através da taxação, ${ }^{17}$ o que levou Finley a afirmar que:

Para provê-lo [o exército] de alimentos, vestuários, armas e transporte, ampliou enormemente o sistema de contribuições compulsórias em espécie, que passou a incidir sobre a maior parte da população do Império. (Finley, 1991, p. 169)

Para Finley, o exército era a pedra angular da reorganização de Diocleciano, estando todos os esforços administrativos voltados a este mantenedor da integridade do Império.

Entretanto, a crítica historiográfica atual ${ }^{18}$ refuta estas afirmações, defendendo a ideia de que estes números são exagerados, uma vez que os imperadores se encontravam diante de dificuldades de recrutamento, além da perda de efetivos nas guerras.

Neste sentido, as causas para o aumento da taxação repousariam na complexificação político-administrativa, cujas variáveis seriam o fortalecimento da rede administrativa; a corte, as pressões externas e as reformas militares implicaram a ampliação dos custos com a complexidade político-administrativa e explicam a necessidade da reforma fiscal e monetária. ${ }^{19}$

Os novos parceiros eram Constâncio (293-306) e Galério Maximiano (293-311): o primeiro um general a quem se atribuía uma origem nobre - uma ascendência, possivelmente

\footnotetext{
${ }^{16}$ Panegíricos latinos II (X), 5, 3; Lactâncio, Sobre a morte dos perseguidores, VIII, 2.

${ }^{17}$ Lactâncio, Sobre a morte dos perseguidores, VII, 1-2. Para Lactâncio, a formação da Tetrarquia se relacionava ao desejo de Diocleciano de satisfazer sua avareza natural pela divisão do mundo romano para efeito de taxação. A taxação é consequência da necessidade do aumento de efetivos militares, capazes de fazer frente a tantas frontes de batalha. Cf. Parker, 1933, p. 175-189; Nischer, 1923, p. 1-55.

${ }^{18}$ Corcoran, 2006; Goldsworthy, 2003; Williams, 1985.

${ }^{19}$ Mendes, 2002, p. 135-165.
} 
forjada, do imperador Cláudio II, o Gótico (268-270) -, ${ }^{20}$ o segundo, um homem humilde ao qual Lactâncio atribui uma ascendência bárbara. ${ }^{21}$

Da mesma forma que Diocleciano e Maximiano Hercúleo eram, como Augustos, filhos de Júpiter e Hércules, Galério se tornou o filho de Diocleciano, e, por sua vez, Joviano, enquanto Constâncio se tornou o filho de Maximiano, e Hercúleo.

Não obstante, a partir dos vestígios numismáticos, podemos rastrear que os Césares não apenas se ligaram aos deuses protetores de seus pais, como também, eles próprios, se associaram a outras divindades. No caso de Constâncio a Marte, e no caso de Galério ao Sol Invictus. ${ }^{22}$

Ambos os nobilissimi Caesari entraram na gens Valeria, a qual Diocleciano e Maximiano pertenciam. A Casa Imperial tetrárquica encontrava-se reunida sob a autoridade estrita do Augusto Joviano, Diocleciano, e pelo compromisso da pietas - o senso de dever entre deuses e homem.

Como bem sintetizado por Norma Musco Mendes e Gilvan Ventura da Silva:

O sistema tetrárquico, portanto, baseava-se em três princípios: a hierarquia, fixada pela antiguidade no cargo; a cooptação entre Césares no reconhecimento da preeminência dos Augustos e os vínculos familiares de adoção e casamento. (Silva; Mendes, 2006, p. 200)

A nomenclatura Joviana e Hercúlea, além de invocar um direito divino legitimatório do sistema político tetrárquico, permitia igualmente a Diocleciano se utilizar de motivos mitológicos tradicionais, em suas representações, como forma simbólica que explicava a realeza sagrada e o relacionamento e funções dos Augustos.

Os Panegíricos latinos, especialmente os dedicados a Maximiano Hercúleo - o Mamertini panegyricus Maximiano Augusto dictus, e o Genethliacus Maximiano Augusto -, estabeleceram releituras dos mitos olímpicos, relacionando-os às ações de Maximiano e Diocleciano.

Por exemplo, um dos temas mais recorrentes refere-se a Iuppiter Optimus Maximus como o mantenedor do Império Romano, o deus que submeteu a antiga raça dos Titãs e fundou uma nova raça dos Olímpicos. ${ }^{23}$

Através da escolha de Júpiter como seu "pai divino", Diocleciano imputava a si a responsabilidade pela derrota dos inimigos que se punham a sua frente-fossem usurpadores, bárbaros, ou persas -, afirmando sua legitimidade e identificando-se como a fonte da autoridade dos demais imperadores, além de ser o fundador de uma nova "Era de Ouro". ${ }^{24}$

\footnotetext{
${ }^{20}$ Panegíricos latinos VII (VI), 2,1; SHA Diuus Claudius VIII, 3.

${ }^{21}$ Lactâncio, Sobre a morte dos perseguidores, IX, 1-3.

${ }^{22}$ Odahl, 2004, p. 55.

${ }^{23}$ Panegíricos latinos III (XI), 3, 4.

${ }^{24}$ Panegiricos latinos II (XI), 1, 5; 3, 1; III, 15, 2-4; V, 18, 5.
} 
Por sua vez, a escolha de Hércules como o antepassado divino de Maximiano, representava que Diocleciano revestiu seu colega de forma similar ao que Júpiter fez no mito de Hércules, engendrou um herói para purgar o mundo dos homens. ${ }^{25}$

Assim, os governantes relacionaram-se diretamente ao panteão greco-romano e à mitologia, como um modo de representação, propaganda e legitimação do novo sistema político.

Afora a explicação da divisão de poderes, os epítetos Joviano e Hercúleo também se relacionavam à afirmação do direito divino dos imperadores, e à reivindicação de que a Tetrarquia seria o estilo ideal de governo porque refletiria a estrutura do cosmo.

Era ideia comum no pensamento político-religioso greco-romano, desde o período helenístico, que um governo estável reproduzisse na Terra o governo dos céus. Assim, nada mais razoável que a explicação dada no panegírico de 289, no qual os poderes de Diocleciano e Maximiano emanavam de "Júpiter, senhor do céu, e de Hércules, pacificador da terra". ${ }^{26}$

\section{Atributos místicos E O CARÁter do PODER IMPERIAL}

A ênfase nos atributos divinos de legitimidade do poder imperial relacionavase diretamente com o desenvolvimento de um ideário e mística imperiais em torno de Diocleciano e Maximiano que, na linguagem pomposa dos panegíricos, apresentavam-se como co-participes da natureza divina de Júpiter e Hércules.

O exemplo mais interessante desta epifania entre os Augustos e os deuses é-nos apresentado por Mamertino:

Mas agora, tão logo como em uma e outra montanha dos Alpes luziu vossa divindade, sobre a Itália se difundiu uma luz mais brilhante e todos os que haviam levantado os olhos ficaram estupefatos ao mesmo tempo em que se perguntavam que deuses se alçavam nos cumes desses montes e se eles se utilizavam desses degraus para baixarem do céu à terra. Mas quando, à medida que ias te aproximando, as pessoas começaram a reconhecê-los, todos os campos se encheram não somente de homens que haviam acudido correndo, como também de rebanhos de animais que abandonavam seus pastos longínquos e os bosques; os camponeses corriam de uns a outros e anunciavam em todas as aldeias o que haviam visto: sobre os altares se acendiam fogueiras, se vertiam sobre elas incenso, se faziam sobre elas libações de vinho, se imolavam vítimas; em todas as partes havia danças e se ouviam palmas; o povo cantava aos deuses imortais cantos de louvor e gratidão; o povo invocava a Júpiter, não

\footnotetext{
${ }^{25}$ Grimal, 2005, p. 205-221.

${ }^{26}$ Panegíricos latinos II (X), 11, 6 .
} 
ao que nos legou a lenda, mas ao visível e presente; o povo adorava a um Hércules que não era um estrangeiro, mas o imperador. ${ }^{27}$

Quando a Tetrarquia já era uma realidade consumada, um panegirista anônimo expôs que a relação existente entre os quatro imperadores encontrava-se em perfeita harmonia cósmica, e desta forma refletia na Terra o arquétipo celeste:

Ademais, independentemente dos interesses e do cuidado da República, esta majestade que aparenta com Júpiter e com Hércules os príncipes joviano e hercúleo, exigia para eles algo semelhante ao que existe no universo inteiro e no mundo celeste. Pois este número de quatro, símbolo de vosso poder, é a força e a alegria de quanto há de maior: assim, os elementos são quatro, quatro as estações, quatro as partes do mundo divididas pelo duplo oceano, e os quinquênios regressam após uma quádrupla revolução dos céus, e são quatro os cavalos do Sol, e aos dois brilhos do céu vêm a se adicionar Vésper e Lúcifer. ${ }^{28}$

Com a adoção deste sistema, Diocleciano esperava evitar um perigoso interregno à morte de um imperador, como ocorreu anteriormente, e exaltar o prestígio e a autoridade do cargo imperial.

As reformas de Diocleciano impuseram uma administração muito mais estrita ao Império, o que ocorreu paralelamente a um projeto de maior homogeneização, como bem apresentou Elizabeth Digeser (2000, p. 30): a legitimidade político-religiosa do sistema político repousava na ideia de que a unidade e a paz dependiam do culto universal das deidades tradicionais. ${ }^{29}$

\footnotetext{
${ }^{27}$ Panegíricos latinos III (XI), 10, 4-5 (Tradução nossa). Nunc autem, ut primum ex utrisque Alpium ingis uestrum numem effulsit, tota Italia clarior lux diffusa, omnibus qui suspexerant aeque admiration atque dubitation iniecta, esquinqm di de illis montium uerticibus orirentur, an his gradibus in terras caelo descenderent. Vt uero propius propiusque coepti estis agnosci, omnes agri oppleti non hominibus modo ad uisendum procurrentibus sed etiam pecudum gregibus remota pascua et nemora linquentibus, concursare inter se agricolae, nuntiare totis $\langle$ suis $>$ uisa, area incendi, tura poni, uina libari, nictimae caedi, cuncta gaudio calere, cuncta plausibus tripudiare, dis immortalibus laudes gratesque cantari, non opinione traditus sed conspicuous et praesens Iuppiter cominus inuocari, non aduena sed imperator Hercules adorari.

${ }^{28}$ Panegíricos latinos V (VIII), 4, 1-2 (Tradução nossa). Et sane praeter usum curamque rei publicae etiam illa Iouis et Herculis cognata maiestas in Iouio Herculioque principibus totius mundi caelestiumque rerum similitudinem requirebat. Quippe isto numinis uestri numero summa omnia nituntur et gaudent, elementa quattuor et totidem anni uices et orbis quadrifariam duplici discretus Oceano et emenso quarter caelo lustra redeuntia et quadrigae Solis et duobus caeli luminibus adiuncti Vesper et Lucifer.

${ }^{29}$ Cf. também Odahl, 2004, p. 54-55.
} 
Tendo por objetivo estruturar legalmente seu reordenamento do Império Romano, Diocleciano encarregou seus juristas de compilar as leis romanas, resultando em dois códigos de leis entre 291-295..$^{30}$

Os governantes romanos direcionaram, então, seus esforços para formar um governo baseado na lei e na religião, cada vez mais centralizadas - cujo ideal era o do pius ciuis, o cidadão piedoso que manteria o relacionamento correto com a lei romana e os deuses de Roma. ${ }^{31}$

A pietas tradicional foi a base da tentativa de restituição do Império empreendida por Diocleciano; reafirmando a relação correta de Roma com suas deidades protetoras, não apenas para fortalecer a Tetrarquia e revigorar o sistema legal, mas também para mostrar a gratidão pelos longos anos de reinado dos imperadores, prova contundente da fortuna, e da aprovação das deidades.

Ao mesmo tempo, as celebrações públicas reuniam todos os cidadãos romanos para celebrar o fim da desordem civil, render graças pelos privilégios e proteções que os deuses garantiam, além de reconhecer abertamente as obrigações que a cidadania trazia. A pietas de Diocleciano voltava-se para a fidelidade às antigas tradições da romanitas.

Neste sentido, as políticas delineadas no período da Tetrarquia desenvolveram as bases de um sistema político baseado na ordem, na lei, e na pietas tradicional, a partir das quais se buscou corrigir a realidade. ${ }^{32}$

No bojo desta preocupação em “ajustar a realidade”, ocorreu a Reforma Monetária de 294, que também apresentou disposições em favor do ideal da romanitas: impôs-se a cunhagem de moedas com legendas exclusivamente em latim, o que obrigou as antigas Casas de Cunhagem gregas, como a de Alexandria, a disseminar moedas com efígies imperiais e legendas latinas.

Assim sendo, podemos fazer a seguinte síntese: a legitimidade da Tetrarquia repousava na tradição romana, na pietas, nos cultos e costumes dos antepassados, na providência divina, e no reforço do ideal de romanitas.

Neste sentido, os motivos de dominação - que se encontram vinculados às estratégias individuais dos membros das elites - estabeleciam-se sobre um equilíbrio instável, logo, havia a necessidade de se desenvolver uma crença na legitimidade dos imperadores, através da difusão de uma série de discursos de poder (as cerimônias, os panegíricos, as moedas, as estátuas...).

Seguindo esta linha de raciocínio, podemos relacionar as cerimônias e os panegíricos - que nelas eram pronunciados - às redes de patronato, fundamentais à estruturação do Império Romano, e às estratégias individuais para manutenção e fortalecimento dos poderes

\footnotetext{
${ }^{30}$ Digeser, 2000, p.14 passim; Piganiol, 1949, p. 445.

${ }^{31}$ Digeser, 2000, p. 23-28.

${ }^{32}$ Conforme as disposições presentes no "Edito de Galério" - conservado por Lactâncio (Da morte dos perseguidores, XXIV, 1-5) e por Eusébio de Cesareia (História Eclesiástica, VIII, 17) -, a partir do qual percebemos a preocupação existente na política tetrárquica em "amoldar" tudo "às leis antigas e às regras romanas" (Lactâncio, Sobre a morte dos perseguidores, XXIV, 1) tendo por objetivo principal a manutenção da ordem da Res publica.
} 
na esfera local, e global. Pois o objetivo de um orador eminente, chamado a pronunciar um discurso laudatório perante o imperador, era receber benefícios para si e para a sua cidade.

Seus pronunciamentos eram condizentes com o sistema de representações imperiais, ou a forma como os imperadores queriam se apresentar, e desejavam ser vistos. Os panegiristas enunciaram o ideário imperial, numa época em que a base legitimatória repousava cada vez mais nos atributos sagrados de poder.

Em torno desta realeza sagrada tetrárquica estabeleceu-se um conjunto de ritos, cerimônias, atributos místicos e símbolos de poder:

Vossas túnicas triunfais, os fasces consulares, as cadeiras curuis, este séquito esplendoroso de cortesãos [comitatenses], esta claridade que cinge vossa cabeça divina com um nimbo resplandecente, são os magníficos e augustíssimos ornamentos que se devem a vossos méritos. $^{33}$

Por um lado, o panegirista se referiu aos símbolos tradicionais romanos que, desde o período republicano, figuraram entre os atributos de poder: os fasces consulares e a cadeira curul; por outro, Mamertino incluiu entre estes atributos de poder o comitatus, e o nimbo resplandecente; este último símbolo denota a sacralidade do imperador e sua natureza superior à dos demais homens, conforme anunciou o próprio Mamertino dois anos depois - no Mamertini panegyricus genethliacus Maximiano Augusto dictus:

E logo disto, a virtude que está intimamente vinculada ao culto dos deuses, com quanta piedade vos trateis um ao outro! Que séculos, com efeito, nunca viram uma concórdia semelhante sobre o mesmo poder? Que irmãos, que gêmeos respeitam a igualdade de seus direitos sobre o patrimônio indiviso com tanta equidade como vós o fazeis na administração do mundo romano? Disto se infere com toda evidência que, se as almas dos demais homens são terrenas e perecíveis, as vossas, ao contrário, são celestiais e eternas. (...) Vossa alma imortal, ao contrário, está acima de todo poder, de toda fortuna, acima do próprio império. (...) Deste modo, vossa piedade vos duplica as vantagens e benefícios do poder divino: cada um de vós desfruta a vez de seu império e do de seu associado. ${ }^{34}$

\footnotetext{
${ }^{33}$ Panegíricos latinos II (X), 3, 2 (Tradução nossa). Trabeae uestrae triumphales et faces consulares et sellae curules et haec obsequiorum stipatio et fulgor, et illa lux dininum uerticem claro orbe complectens, uestrorum sunt ornamenta meritorum, pulcherrima quidem augustissima.

${ }^{34}$ Panegíricos latinos III (XI), 6, 3-7 (Tradução nossa). Deinde, id quod maxime deorum immortalium cum religione coniunctum est, quanta nosmet inuicem pietate colitis! Quae enim umquam lidere saecula talem in summa potestate concordiam? Qui germani geminiue frates indiuiso patrimonio tam aequabiliter utuntur quam uos orbe Romano? Ex quo profecto manifestum est ceterorum hominum animas esse humilis et caducas, uestras uero caelestes et sempiternas (...) uester uero immortalis animus omnibus opibus omnique fortuna atque ipso est maior imperio (...) Ita duplices uobis dininae potentiae fructus pietas uestra largitur: et suo uterque fruitur et consortis imperio.
} 
De forma semelhante, as cerimônias apresentam-se como discursos de poder, como o transcrito público ${ }^{35}$ que pretendia reforçar o caráter sagrado e transcendente do poder imperial cujos reflexos eram a submissão, principalmente, dos membros das elites - que eram admitidos nas cerimônias -, como as adorationes, ${ }^{36}$ conforme narradas por Mamertino:

Que momentos aqueles, deuses bondosos! Que espetáculo o que ofereceu vossa piedade quando, em vosso palácio em Milão, aparecestes os dois aos que haviam sido admitidos a adorar vossas sagradas faces e quando a inesperada presença de vossa dupla divindade desconcertou as homenagens que logo se dirigiam a uma só. Ninguém observou a hierarquia das divindades de acordo com o protocolo habitual: todos detiveram o tempo a adorar-vos, tardando em cumprir um duplo dever de piedade. Este ato de adoração, que havia permanecido de certo modo dissimulado no interior de um santuário, havia paralisado de estupor somente as almas daqueles cuja posição entre os dignitários dava acesso à vossa presença. ${ }^{37}$

Isolados e exaltados como nunca anteriormente, os imperadores se cercaram de atributos de um elaborado cerimonial de corte, provido de vestes e pedrarias, sendo uma figura sagrada. O imperador não era mais o primus inter pares, exaltado pelo autor Flávio Eutrópio, ${ }^{38}$ mas um rei, alguém que demandava a adoratio. O imperador é destacado como um dominus, não mais um princeps.

\footnotetext{
${ }^{35}$ Scott, 1990.

${ }^{36}$ Sobre o ritual da adoratio, ver Stern, 1954, p. 184-189.

${ }^{37}$ Panegíricos latinos III (XI), 11, 1-3 (Tradução nossa). Quid illud, di boni! Quale pietas uestra spectaculum dedit, cum in Mediolanensi palatio admissis qui sacros uultus adoraturi erant conspecti estis ambo, et consuetudinem simplicis uenerationis geminato numine repente turbastis! Nemo ordinem numinum solita secutus est disciplina; omnes adorandi mora restiterunt duplicato pietatis officio contumaces. Atque haec quidem uelut interioribus sacrariis operta ueneratio eorum modo animos obstupefecerat quibus aditum uestri dabant ordines dignitatis.

${ }^{38}$ Eutrópio IX, 26: "Diocleciano era de uma astuciosa disposição, com muita sagacidade e perspicaz entendimento. Ele estava disposto a satisfazer sua própria disposição à crueldade de tal modo que lançou o ódio sobre os demais; ele foi, porém, um príncipe muito ativo e capaz. Ele foi o primeiro a introduzir no Império Romano uma cerimônia que servia mais aos usos reais que à liberdade romana, dando ordens que ele deveria ser adorado, enquanto todos os imperadores antes dele foram apenas saudados. Ele colocou ornamentos de pedras preciosas em suas roupas e calçados, enquanto a distinção imperial anteriormente era só o manto púrpura, nos demais hábitos era como os demais homens" (Tradução nossa). Diocletianus moratus callide fuit, sagax praeterea et admodum subtilis ingenii, et qui severitatem suam aliena invidia vellet explere. Diligentissimus tamen et sollertissimus princeps et qui imperio Romano primus regiae consuetudinis formam magis quam Romanae libertatis invexerit adorarique se iussit, cum ante eum cuncti salutarentur. Ornamenta gemmarum vestibus calciamentisque indidit. Nam prius imperii insigne in chlamyde purpurea tantum erat, reliqua communia.
} 


\section{Considerações finais}

Com o estabelecimento da Tetrarquia, podemos observar que a representação do poder imperial se baseou na releitura e na apropriação de temas tradicionais, que acabaram por fundamentar um sistema político que refletia um cosmos no qual Júpiter reinava supremo (embora auxiliado por outras deidades); isto explicava as relações de poder através de analogias com a mitologia, e referendava o deus Júpiter como a fonte última do poder dos imperadores.

Baseado em seu ideal de romanitas, Diocleciano confiava que seus súditos continuassem devotados ao tradicional panteão greco-romano. Consequência desta devoção seria a justificação desta dominação carismático-tradicional baseada no apoio das divindades acompanhantes.

A importância que a Tetrarquia atribuiu ao culto tradicional - em particular ao culto de Júpiter e Hércules - é evidência de seus esforços em fortalecer o culto dos deuses protetores da Res publica, como aventa Elizabeth Digeser (2000, p. 30): "lealdade à Tetrarquia desta forma exigia fidelidade ao culto tradicional". 39

Neste sentido, buscamos verificar como este processo de mudança engendrou novas representações políticas do poder imperial romano, através da conexão entre cultura e poder, uma vez que o estabelecimento do governo colegiado por Diocleciano baseou-se no uso dos lugares comuns retóricos da concórdia e da unidade em sua relação com as práticas de representação e com os rituais de poder durante o período entre os anos 284 e 305.

\section{REFERÊNCIAS}

AGUIRRE ROJAS, Carlos Antonio. Antimanual do mau historiador. Ou como se fazer uma boa bistória crítica? 'Tradução Jurandir Malerba. Londrina: EdUEL, 2007.

ANDERSON, J.G.C. The Genesis of Diocletian's Provincial Re-Organization. The Journal of Roman Studies, vol. 22, p. 24-32, 1932.

BAYNES, Norman. Three Notes on the Reforms of Diocletian and Constantine. The Journal of Roman Studies. vol. 15, p. 195-208, 1925.

BÉRANGER, Jean. Principatus. Études de notions et d'bistoire politiques dans l'Antiquité gréco-romaine. Gèneve: Librairie Droz, 1973.

CASEY, P.J. Carausius and Allectus - Rulers in Gaul? Britannia, vol. 8, 1977, p. 283-301.

CIZEK, Eugène. L'empereur Aurélien et son temps. Paris: Les Belles Lettres, 1994.

CORCORAN, Simon. Before Constantine. In LENSKI, Noel (ed.). Age of Constantine. Cambridge: Cambridge University Press, 2006, p. 35-59.

DIGESER, Elizabeth DePalma. The making of a Christian Empire: Lactantius and Rome. Ithaca: Cornell University Press, 2000.

\footnotetext{
${ }^{39}$ Opinião próxima encontra-se em Williams, 2000, p. 69-70.
} 
ERIM, Kenan T.; REYNOLDS, Joyce; CRAWFORD, Michael. Diocletian's Currency Reform. A New Inscription. The Journal of Roman Studies, vol. 61, p.171-177, 1971.

ESCOBAR BAREÑO, Luis et alii. Biógrafos y panegiristas latinos. Madrid: Aguilar, 1969.

EUSÉBIO DE CESAREIA. História Eclesiástica. Tradução Monjas Beneditinas do Mosteiro Maria Mãe de Cristo. São Paulo: Paulus, 2000.

FINLEY, Moses. I. Aspectos da Antiguidade. São Paulo: Martins Fontes, 1991 [1960-68].

FLAVIO EUTROPIO. Eutropius: Breniarium. Edited and translated by H. W. Bird. Liverpool: Liverpool University Press, 1993.

GOLDSWORTHY, A. The Complete Roman Army. London: Thames \& Hudson, 2003.

GRIMAL, Pierre. Dicionário da mitologia grega e romana. Tradução de Victor Jabouille. Rio de Janeiro: Bertrand Brasil, 2005.

HENDY, Michael. Mint and Fiscal Administration under Diocletian, His Colleagues, and His Successors A.D. 305-24. The Journal of Roman Studies, vol. 62, p. 75-82, 1972.

In Praise of Later Roman Emperors: The PANEGYRICI LATINI. Introduction, Translation, and Historical Commentary C.E.V. Nixon and Barbara Saylor Rodgers. With Latin Text of R. A. B. Mynors. Berkeley: University of California Press, 1994.

JOHNSON, Allan Chester. Roman Egypt to the Reign of Diocletian. Baltimore, London: Johns Hopkins Press, 1936.

JONES, A. H. M. Inflation under the Roman Empire. The Economic History Review. New Series, vol. 5, n. 3, p. 293-318, 1953.

JONES, A. H. M. The Later Roman Empire, AD 284-602. v.1. Oxford: Blackwell, 1964.

KALAVREZOU-MAXEINER, Ioli. The imperial chamber at Luxor. Dumbarton Oaks Papers, vol. 29, p. 225-251, 1975.

LACTANCE. De la mort des persécuteurs. Introduction, texte critique et tradution Jacques Moreau. Paris: Éditions du Cerf, 1954.

LACTANTIUS. De mortibus persecutorum. Edited and translated by J. L. Creed. Oxford: Clarendon Press, 1985.

MacMULLEN, Ramsay. Le déclin de Rome et la corruption du pouvoir. Paris: Les Belles Lettres, 1991.

MacMULLEN, Ramsay. Imperial Bureaucrats in the Roman Provinces. Harvard Studies in Classical Philology, vol. 68, p. 305-316, 1964.

MATTINGLY, H. The Mints of the Empire: Vespasian to Diocletian. The Journal of Roman Studies, vol. 11, p. 254-264, 1921. 
MICHELL, H. The Edict of Diocletian: a study of price fixing in the Roman Empire. The Canadian Journal of Economics and Political Science / Revue canadienne de economiques et science politique. vol. 13, n.1, p. 1-12, Feb. 1947.

NISCHER, E. C. The Army Reforms of Diocletian and Constantine and Their Modifications up to the Time of the Notitia Dignitatum. The Journal of Roman Studies, vol. 13, p. 1-55, 1923. ODAHL, Charles Matson. Constantine and the Christian Empire. London: Routledge, 2004.

PARKER, H. M. D. The legions of Diocletian and Constantine. The Journal of Roman Studies, vol. 23, p. 175-189, 1933.

PIGANIOL, André. Histoire de Rome. Paris: Presses Universitaires de France, 1949

REES, Roger. Images and Image: A Re-Examination of Tetrarchic Iconography. Greece \& Rome, vol. 40. n. 2, p. 181-200, Oct. 1993.

RODRIGUES GERVÁS, Manuel J. Propaganda política y opinión publica en los Panegíricos Latinos del Bajo Imperio. Salamanca: Universidad de Salamanca, 1991.

SCOTT, James C. Domination and the Arts of Resistence: Hidden Transcripts. New Haven/London: Yale University Press, 1990.

SILVA, Gilvan; MENDES, Norma. Diocleciano e Constantino. In: SILVA, Gilvan; MENDES, Norma. Repensando o Império Romano. Rio de Janeiro/Vitória: Mauad/EdUFES, 2006

SPERBER, Daniel. Denarii et Aurei in the time of Diocletian. The Journal of Roman Studies, vol. 56, p.190-195, 1966.

STERN, H. Remarks on the "Adoratio" under Diocletian. The Journal of the Warburg and Courtauld Institutes, vol. 17, p. 184-189, 1954.

SUTHERLAND, C. H. V. Diocletian's Reform of the Coinage: a chronological note. The Journal of Roman Studies, vol. 45, p. 116-118, 1955.

SUTHERLAND, C. H. V. Denarius and Sestertius in Diocletian's Coinage Reform. The Journal of Roman Studies, vol. 51, p. 94-97, 1961.

SUTHERLAND, C. H. V. Some Political Notions in Coin Types between 294 and 313. The Journal of Roman Studies, vol. 53, p. 14-20, 1963.

SUTHERLAND, C. H. V. The Roman Imperial Coinage. v. VI. London: Spink \& Son, 1967.

VAN DAM, R. Leadership and Community in Late Antiquity Gaul. Berkeley: University of California Press, 1985.

WALLACE, Sherman LeRoy. Taxation in Egypt from Augustus to Diocletian. Princeton: Princeton University Press, 1938. 
WATSON, Alaric. Aurelian and the Third Century. London \& New York: Routledge 1999.

WEST, Louis C. Notes on Diocletian's Edict. Classical Pbilology, vol. 34. n. 3, p. 239-245, Jul. 1939.

WILLIAMS, S. Diocletian and the Roman Recovery. London: Routledge, 1985. 